\title{
BMJ Open Dyspareunia in HIV-positive and HIV-negative middle-aged women: a cross-sectional study
}

\author{
Ana L R Valadares, ${ }^{1}$ Aarão M Pinto-Neto, ${ }^{1}$ Debora de C Gomes, ${ }^{1}$ \\ Walquíria C D'Avanzo, ${ }^{2}$ Alexandre S Moura, ${ }^{3}$ Lúcia Costa-Paiva, ${ }^{1}$ \\ Maria Helena de Sousa ${ }^{1}$
}

To cite: Valadares ALR, Pinto-Neto AM, Gomes D de $\mathrm{C}$, et al. Dyspareunia in HIVpositive and HIV-negative middle-aged women: a cross-sectional study. BMJ Open 2014;4:e004974. doi:10.1136/bmjopen-2014004974

- Prepublication history for this paper is available online. To view these files please visit the journal online (http://dx.doi.org/10.1136/ bmjopen-2014-004974).

Received 4 February 2014 Revised 19 June 2014 Accepted 30 June 2014

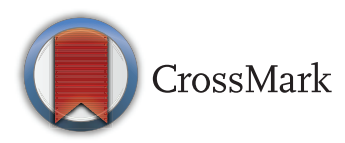

${ }^{1}$ Department of Obstetrics and Gynecology, School of Medical Sciences, University of Campinas (UNICAMP), Campinas, São Paulo, Brazil ${ }^{2}$ Department of Obstetrics and Gynecology, Graduated Student of Medicine of School of Medical Sciences, University of Campinas (UNICAMP), Campinas, São Paulo, Brazil

${ }^{3}$ Department of Municipal Health Division, Infectious Disease Reference Center, CTR/DIP Orestes Diniz, Federal University of Minas Gerais, Belo Horizonte, Minas Gerais, Brazil

Correspondence to Dr Ana Lúcia Ribeiro Valadares;

anarvaladares@gmail.com

\section{ABSTRACT}

Objectives: To evaluate whether dyspareunia is associated with HIV status in menopausal women and also to assess which factors are associated with dyspareunia in a group of HIV-positive menopausal women.

Methods: A cross-sectional study was conducted with 178 HIV-negative and 128 HIV-positive women aged 40-60 years. The Short Personal Experiences Questionnaire (SPEQ) was used to collect data. Sociodemographic, clinical, behavioural and reproductive factors were evaluated, as well as factors related to the HIV infection. Dyspareunia was defined as pain during intercourse. A bivariate analysis and Poisson multiple regression analysis were performed.

Results: Overall, $41.4 \%$ of the HIV-positive women reported dyspareunia compared with $34.8 \%$ of the HIVnegative women ( $p=0.242)$. In the HIV-positive women, bivariate analysis revealed an association between dyspareunia and having a steady partner $(p=0.047)$; the woman's partner having undergone HIV testing $(p=0.020)$; vaginal dryness $(p<0.001)$; muscle/joint pain $(p=0.021)$; physical/emotional violence $(p=0.049)$; urinary incontinence $(p=0.004)$; and the use of lamivudine/zidovudine $(p=0.048)$. The Poisson multiple regression analysis found an association between dyspareunia and vaginal dryness ( prevalence ratio (PR) $=1.96,95 \% \mathrm{Cl} 1.10$ to $3.50, \mathrm{p}=0.023$ ) and urinary incontinence (PR=1.86, 95\% Cl 1.06 to $3.27, \mathrm{p}=0.031$ ). Conclusions: Dyspareunia was common in this group of HIV-positive women and was associated principally with vaginal dryness and urinary incontinence. The importance of treating dyspareunia within the context of sexual health in this group of women should be emphasised and appropriate management of this issue may reduce the likelihood of lesions on the vaginal wall, which may act as a portal of entry for other infections.

\section{INTRODUCTION}

Dyspareunia is defined as persistent or recurrent genital pain that occurs just before, during or after intercourse. It is one of the most common problems reported by menopausal

\section{Strengths and limitations of this study}

- We have not found studies on dyspareunia in HIV-positive women.

- We have highlighted the importance of vulvovaginal atrophy and its association with dyspareunia in middle-aged HIV-positive women.

- We have shown that HIV infection was not significantly associated with dyspareunia, probably because HIV-positive women had few HIV-related symptoms.

- The results of this study may help physicians to focus attention on vulvovaginal atrophy and its consequences in this group of HIV-positive women.

- It is a cross-sectional design study.

- There were some differences in the clinical characteristics of the HIV-positive and HIV-negative women.

women. The variation in the frequency of dyspareunia probably reflects many issues including sociocultural aspects, the period of observation during which the condition was evaluated (ever, the past year) and the duration or design of the study under discussion (questionnaire wording, participants). ${ }^{1}$

For women of all ages, the pain caused by dyspareunia often results in distress, impaired sexual functioning and poor sexual enjoyment, difficulty in relationships and a poorer quality of life. In postmenopausal women, dyspareunia may also intensify personal issues related to ageing, body image and health. ${ }^{2}$

As with most of the sexual difficulties faced by women in midlife and beyond, dyspareunia is typically considered a consequence of declining ovarian hormone levels and is usually attributed to vaginal atrophy; ${ }^{3}$ however, other factors may also be involved. ${ }^{4}$ In fact, psychosexual and biological factors (including muscular, endocrine, immune, neurological, vascular and iatrogenic factors) that predispose to, precipitate and perpetuate the condition may interact with different degrees in the 
individual woman, contributing to a continuum of symptoms of increasing severity, with the potential to impair sexual intercourse. ${ }^{5}$ Age, ${ }^{6}$ depression, anxiety and sexual dysfunction in the partner ${ }^{45}$ are some of the other factors associated with dyspareunia. It seems that cognitiveemotional variables (catastrophisation, depression, anxiety) are significant predictors of dyspareunia and relationship adjustment variables were inversely associated with pain severity. ${ }^{7}$ Findings also suggest that dyspareunia impacts the psychosexual adjustment of affected women as well as of their partners. ${ }^{8}$

Menopausal women who are HIV positive may present a unique set of issues that could affect their sexuality. These issues may include the meaning of their illness, their quality of life, HIV transmissibility, and the dilemma of whether or not to disclose the condition to their partner. Florence et at reported sexual dysfunction to be common in HIV-positive women, principally as a result of their HIV status and of psychological factors that included depression, irritability and anxiety. On the other hand, women with better mental health after HIV diagnosis, a more positive attitude towards living with HIV, a better quality of life, fewer HIV-related symptoms and who had never used injectable drugs were found to have better sexual functioning. ${ }^{10}$ A possible role of antiretroviral drugs in causing sexual dysfunction has been a matter of debate. While some studies have suggested that antiretroviral therapy (ART) indeed plays a role in sexual function, others have failed to find any such association. ${ }^{11}$

The majority of studies on dyspareunia have failed to deal with factors associated with HIV infection, a topic yet to be fully investigated in HIV-positive women during the ageing process. Therefore, the objectives of the present study were to evaluate whether dyspareunia is associated with HIV status in middle-aged women and to assess the factors associated with dyspareunia in HIV-positive middle-aged women.

\section{METHODS}

\section{Study design}

A cross-sectional study was conducted in 537 women aged 40-60 years, of whom 273 were HIV-positive and 264 were HIV-negative and screened for inclusion. Patients were recruited at the infectious diseases and HIV outpatient clinics (HIV-positive women) and at the menopausal ambulatory care (HIV-negative women), both at the Teaching Hospital of the University of Campinas (UNICAMP). Patients were also invited to participate at the infectious diseases outpatient public clinic (HIV-positive women) in Belo Horizonte. Of these, 178 HIV-negative women and 128 HIV-positive women had had vaginal intercourse in the previous month and were willing to answer a questionnaire on dyspareunia. These women were then admitted to the study.

For inclusion in the HIV-positive group, laboratory confirmation of the women's seropositive status by one of the recommended tests (ELISA or Western Blot) was required (all of them had it), while the women recruited to the HIV-negative group had to have tested negative. The blood sample tests of HIV-negative and HIV-positive women were collected at the moment of admission in this study (follicle stimulating hormone (FSH), luteinising hormone (LH) and thyroid stimulating hormone for all; ELISA or Western Blot HIV tests for HIV-negative women; and Viral load and CD4 cells for HIV-positive women). Exclusion criteria consisted of nursing mothers, bilaterally oophorectomised women and those unable to answer the questionnaire. The evaluation instrument was the Short Personal Experiences Questionnaire (SPEQ). ${ }^{12} 13$ Sociodemographic, clinical, behavioural and reproductive characteristics were assessed as well as issues relating to the HIV infection and partner-related factors.

\section{Dependent variable}

The dependent variable dyspareunia, defined as pain during sexual intercourse, was graded from 1 to 6 , where 1 referred to the absence of pain and 6 to maximum pain. A score of less than two was considered to represent the absence of dyspareunia and a score of two or more to represent the presence of dyspareunia. ${ }^{42} 13$

\section{Independent variables}

The independent variables were dichotomised as follows: HIV status (positive/negative); skin colour (white/other); marital status (has a stable partner/no stable partner); schooling ( $\leq 7$ years $/ \geq 8$ years); employment (yes/no); monthly family income $(\leq \mathrm{US} \$ 750 />\mathrm{US}$ $\$ 750$ ); receives pension (yes/no); smokes (yes/never or ex-smoker); alcohol use (currently drinks or used to drink/never drank); hot flushes (yes/no); depression (yes/no); vaginal dryness (yes/no); urinary incontinence (yes/no); weight gain (yes/no); muscle and joint pain (yes/no); self-perception of health (excellent or good/poor or very poor); suffers or has already suffered some form of physical or emotional violence (yes/no); has been forced to have intercourse (yes/no); uses statins (yes/no); chronic disease: hypothyroidism (yes/no); FSH $(<40 / \geq 40)$, LH $(<25.7 / \geq 25.7)$; age at first sexual intercourse ( $\leq 19$ years $/ \geq 20$ years); other type of sexual intercourse in the preceding month: giving oral sex (yes/no), receiving oral sex (yes/no); woman lives with sexual partner (yes/no); number of sexual partners in the previous year (none/ $\geq 1$ ); partner underwent HIV testing (yes/no); quality of life following diagnosis (changed/unchanged); CD4 cell count $(<350 / \geq 350)$; CD4 cell count nadir $(<199 / \geq 200)$; use of antiretroviral drug 3TC (lamivudine, Epivir; yes/no); use of antiretroviral drug tenofovir (yes/no); use of antiretroviral drug lamivudine/zidovudine (yes/no); use of antiretroviral drug efavirenz (yes/no); antiretroviral drug used in the past: lamivudine/zidovudine (yes/no); and antiretroviral drug used in the past: efavirenz (yes/ no). Menopausal status was classified as premenopausal, perimenopausal or postmenopausal. Women were considered premenopausal if they continued to have 
regular menstrual cycles similar to those present during the woman's reproductive life. They were considered to be in the perimenopause if their menstrual cycles were irregular and they had been amenorrhoeic for less than 12 months. Finally, women were classified as postmenopausal if they had been amenorrhoeic for 12 months or more. ${ }^{14}$ Data on physical activity was obtained through two questions: Do you practise physical exercise or participate in sports every week? How often in a week do you practise physical exercise or participate in sports? It was classified in up to two times a week or three or more times a week. Vaginal lubrication during sexual activity was graded from 1 to 6 , where 1 referred to the absence of lubrication and 6 to maximum lubrication. This was dichotomised into four or less or more than four.

\section{Statistical analysis}

A bivariate analysis was performed in which dyspareunia was considered the dependent variable (dyspareunia) and analysed as a function of the independent variables. Pearson's $\chi^{2}$ test and the Yates correction were used to compare the groups. ${ }^{15}$ The Poisson multiple regression analysis ${ }^{16}$ was adjusted in the various models for each one of the independent variables to evaluate the factors associated with the presence of dyspareunia.

\section{Ethics}

The study was approved by the internal review board of CAISM/UNICAMP and was conducted in compliance with the current version of the Declaration of Helsinki and with Resolution 196/96 of the Brazilian National Committee for Ethics in Research (CONEP) and its subsequent revisions. This study forms part of a larger study evaluating menopausal symptoms, bone mass, sexual function and metabolic markers. Process: CEP: 407/ 2010, CAAE 0313.0.146.000-10.

Women who agreed to participate in the study after receiving instructions from the researchers and who signed a free informed consent form were included.

\section{RESULTS}

The HIV-positive women were younger and less likely to have a steady partner, to be employed or to have a formal education compared with the HIV-negative women. More than half the HIV-positive women were premenopausal or perimenopausal. The characteristics of the women interviewed are shown in table 1 .

Overall, $41.4 \% \quad(n=53)$ of the HIV-positive women and $34.8 \%(\mathrm{n}=62)$ of the HIV-negative women reported dyspareunia. There was no association between HIV status and dyspareunia $(p=0.242)$. Furthermore, in the multiple regression analysis of the entire sample of HIV-positive and HIV-negative women taken together ( $\mathrm{n}=306)$, dyspareunia was not associated with HIV status, but was associated with vaginal dryness (prevalence ratio $(\mathrm{PR})=2.06,95 \%$ CI 1.37 to $3.10, \mathrm{p}=0.001)$ and urinary incontinence ( $\mathrm{PR}=1.68,95 \%$ CI 1.14 to $2.46, \mathrm{p}=0.008)$.
In the HIV-positive group, $91.4 \%$ of the women were currently using ART, and of these $87 \%$ reported using ART regularly (data not presented as a table). Approximately $77 \%$ of the HIV-positive women had a CD4 cell count nadir $>200$. The most common way in which HIV had been acquired was by heterosexual transmission, and the average duration of the HIV infection was 9.5 \pm 5.6 years $($ mean $\pm \mathrm{SD})$, with a mean duration of therapy of 8.7 years $\pm 4.5(\mathrm{mean} \pm \mathrm{SD})$. A more detailed description of the HIV-infected women is provided in table 2.

Bivariate analysis revealed an association between dyspareunia in the HIV-positive women and having a steady partner $(\mathrm{p}=0.047)$; the woman's partner having undergone HIV testing $(p=0.020)$; vaginal dryness $(p<0.001)$; muscle/joint pain ( $\mathrm{p}=0.021)$; physical/emotional violence $(p=0.049)$; urinary incontinence $(p=0.004)$; and the use of lamivudine/zidovudine $(\mathrm{p}=0.048)$, table 3 .

According to the Poisson multiple regression analysis, the principal factors associated with dyspareunia in the group of HIV-positive women were: vaginal dryness $(\mathrm{PR}=1.96 ; 95 \%$ CI 1.10 to $3.50 ; \mathrm{p}=0.023)$ and urinary incontinence $(\mathrm{PR}=1.86 ; 95 \%$ CI 1.06 to $3.27 ; \mathrm{p}=0.031$; table 4).

\section{DISCUSSION}

The objectives of this study were to evaluate whether HIV status was associated with dyspareunia and to assess the factors associated with pain during sexual intercourse in HIV-positive women aged 40-60 years.

The calculated number of women required for the sample size was 74 per group; ${ }^{4}$ however, to enable analysis of the HIV-positive group alone, the required number was 188 women. ${ }^{17}$ Since the actual sample size achieved was 128 , the absolute difference was $8.5 \%$, acceptable since it is less than $10 \%$.

Information on dyspareunia in HIV-positive women is scarce, especially in middle-aged women. To the best of our knowledge, no other studies have been conducted on dyspareunia in HIV-positive women. It has been reported that sexual function in HIV-positive women may be driven principally by psychological factors and other problems related to HIV infection. ${ }^{17} 18$ This study, however, found that in the overall sample of HIV-positive and HIV-negative women dyspareunia was not affected by HIV status. This finding is in agreement with the results of another author, who also reported that few women believed HIV in itself to be the cause of any decline in their sexual functioning, since those women had good immunovirological status. ${ }^{10}$ One supposes that results would be different in a sample of women without good HIV control. In this study, more than threequarters of the HIV-positive patients had a CD4 cell count nadir $>200$ and CD4 cell counts $>500$ in their last evaluation, thus reflecting adequate control of the disease. This may partially explain why no association was found between HIV status and dyspareunia. In line with this, another study showed that women with CD4 
Table 1 Some characteristics of women according to HIV status

\begin{tabular}{|c|c|c|c|}
\hline \multirow[b]{2}{*}{ Characteristic } & \multicolumn{3}{|l|}{ Group } \\
\hline & HIV-infected (\%; n=128) & HIV-uninfected (\%; n=178) & p Value \\
\hline \multicolumn{4}{|l|}{ Age (years) } \\
\hline $40-44$ & 43.8 & 24.7 & \multirow[t]{4}{*}{$<0.002^{*}$} \\
\hline $45-49$ & 28.9 & 29.2 & \\
\hline $50-54$ & 15.6 & 23.1 & \\
\hline$\geq 55$ & 11.7 & 23.0 & \\
\hline \multicolumn{4}{|l|}{ Skin colour } \\
\hline White & 35.2 & 47.2 & \multirow[t]{2}{*}{$0.047 \dagger$} \\
\hline Non-white & 64.8 & 52.8 & \\
\hline \multicolumn{4}{|l|}{ Number of deliveries } \\
\hline Up to 1 & 25.0 & 25.4 & \multirow[t]{2}{*}{$>0.999 \dagger$} \\
\hline$\geq 2$ & 75.0 & 74.6 & \\
\hline \multicolumn{4}{|l|}{ Marital status } \\
\hline With partner & 58.6 & 87.1 & \multirow[t]{2}{*}{$<0.001 \dagger$} \\
\hline Without partner & 41.4 & 12.9 & \\
\hline \multicolumn{4}{|l|}{ Schooling (years) } \\
\hline$\leq 7$ & 62.5 & 40.4 & \multirow[t]{3}{*}{$<0.002^{*}$} \\
\hline $8-11$ & 23.4 & 37.1 & \\
\hline$\geq 12$ & 14.1 & 22.5 & \\
\hline \multicolumn{4}{|l|}{ Employment status } \\
\hline Yes & 59.4 & 71.9 & \multirow[t]{2}{*}{$0.030 \dagger$} \\
\hline No & 40.6 & 28.1 & \\
\hline \multicolumn{4}{|l|}{ Menopausal status } \\
\hline Premenopausal & 39.8 & 24.7 & \multirow[t]{3}{*}{$<0.002^{*}$} \\
\hline Perimenopausal & 28.1 & 21.4 & \\
\hline Postmenopausal & 32.1 & 53.9 & \\
\hline \multicolumn{4}{|l|}{ Current smoking status } \\
\hline Yes/former & 28.1 & 15.2 & \multirow[t]{2}{*}{$0.009 \dagger$} \\
\hline No & 71.9 & 84.8 & \\
\hline \multicolumn{4}{|l|}{ Physical activity } \\
\hline Up to 2 times/week & 77.3 & 74.2 & \multirow[t]{2}{*}{$0.614 \dagger$} \\
\hline$\geq 3$ times/week & 22.7 & 25.8 & \\
\hline
\end{tabular}

counts $\leq 199$ cells $/ \mu \mathrm{L}$ reported poorer sexual functioning compared with those whose cell count was $\geq 200 .^{19}$ Other studies have shown that the CD4 cell count nadir may also have long-term consequences in terms of prognosis and mortality. ${ }^{20}$

Nevertheless, the CD4 cell count nadir and the last $\mathrm{CD} 4$ evaluation were not associated with dyspareunia in this study, probably because of the small number of women with these low values.

The most important factors associated with dyspareunia in the logistic regression analysis, in HIV-positive and HIV-negative groups analysed together, and in the HIV group analysis were vaginal dryness and urinary incontinence, both of which are urogenital disorders associated with oestrogen deficiency. The association between vaginal dryness and pain during sexual intercourse has been well documented in the literature, in addition to its consequence on vulvovaginal health. ${ }^{21-23}$ With respect to the association between urinary incontinence and dyspareunia, the findings of this study are in agreement with the results published by Salonia et $a l,{ }^{24}$ who evaluated 216 women with urinary incontinence and found $44 \%$ of dyspareunia in these women. The type of urinary incontinence was not evaluated in this study. Nevertheless, there is good evidence that the effects of urinary incontinence on sexual functioning are similar irrespective of whether the condition has been classified as stress, urge, mixed incontinence ${ }^{25}$ or even interstitial cystitis. ${ }^{26}$ Urinary incontinence is associated with feelings of embarrassment and inadequacy as well as low self-esteem. It may also be associated with dyspareunia. ${ }^{24}$

Factors associated with dyspareunia in HIV-positive women:

In the bivariate analysis, the fact that the woman's partner had not been tested for HIV was associated with less dyspareunia. It is reasonable to speculate that not knowing her partner's HIV status may in some way 'minimise' a woman's concerns regarding transmission and reduce the probability of tension and dyspareunia. ${ }^{27}$ Another factor related to the sexual partner that was associated with an increase in dyspareunia in the bivariate analysis was the woman having a steady partner, although this association was borderline. One 
Table 2 Characteristics associated to HIV status associated with dyspareunia in women with a sexual partner in the month before the interview $(n=128)$

\begin{tabular}{|c|c|c|}
\hline Characteristics & $\mathbf{N}$ & $\%$ \\
\hline $\begin{array}{l}\text { HIV duration of infection } \\
(n=125 ; \text { years })\end{array}$ & Mean: 9.5 & SD: 5.06 \\
\hline $\begin{array}{l}\text { Duration of HIV therapy } \\
\text { ( } n=93 \text {; years) }\end{array}$ & Mean: 8.7 & SD: 4.47 \\
\hline \multicolumn{3}{|l|}{ Nadir CD4 levels* } \\
\hline $0-100$ & 18 & 14.5 \\
\hline $101-200$ & 10 & 8.1 \\
\hline $201-500$ & 62 & 50.0 \\
\hline \multicolumn{3}{|l|}{ Last CD4 levels* } \\
\hline $0-100$ & 5 & 4.0 \\
\hline $101-200$ & 1 & 0.8 \\
\hline $201-500$ & 43 & 34.7 \\
\hline$>500$ & 75 & 60.5 \\
\hline Total & 124 & 100.0 \\
\hline \multicolumn{3}{|l|}{ HIV risk factor for acquisition } \\
\hline Heterosexual acquisition & 97 & 75.8 \\
\hline Illicit drug use & 3 & 2.3 \\
\hline \multirow[t]{2}{*}{ Blood transfusion } & 2 & 1.6 \\
\hline & 26 & 20.3 \\
\hline Total & 128 & 100.0 \\
\hline \multicolumn{3}{|l|}{ Use of TARV } \\
\hline Yes & 117 & 91.4 \\
\hline No & 11 & 8.6 \\
\hline Total & 128 & 100.0 \\
\hline
\end{tabular}

Table 3 Factors associated with dyspareunia (score $\geq 2$ ) in middle-aged HIV-positive women: bivariate analysis

\begin{tabular}{|c|c|c|c|c|}
\hline \multirow[b]{2}{*}{ Variable } & \multicolumn{4}{|c|}{ Dyspareunia \% } \\
\hline & $\bar{n}$ & Score $\geq 2$ & Score $<2$ & p Value \\
\hline Marital status & & & & 0.047 \\
\hline Married/live together & 75 & 49.3 & 50.7 & \\
\hline Do not live together & 53 & 30.2 & 69.8 & \\
\hline $\begin{array}{l}\text { Did partner have an } \\
\text { HIV test? }\end{array}$ & & & & 0.020 \\
\hline Yes & 88 & 50.0 & 50.0 & \\
\hline No & 27 & 22.2 & 77.8 & \\
\hline Vaginal dryness & & & & $<0.001$ \\
\hline Yes & 53 & 58.5 & 41.5 & \\
\hline No & 71 & 26.8 & 73.2 & \\
\hline Muscular/articular pain & & & & 0.021 \\
\hline Yes & 83 & 49.4 & 50.6 & \\
\hline No & 45 & 26.7 & 73.3 & \\
\hline $\begin{array}{l}\text { Physical/emotional } \\
\text { violence }\end{array}$ & & & & 0.049 \\
\hline Yes & 128 & 55.5 & 44.5 & \\
\hline No & 174 & 32.8 & 67.2 & \\
\hline Urinary incontinence & & & & 0.004 \\
\hline Yes & 41 & 61.0 & 39.0 & \\
\hline No & 87 & 32.2 & 67.8 & \\
\hline Use of biovir & & & & 0.048 \\
\hline Yes & 57 & 29.8 & 70.2 & \\
\hline No & 63 & 49.2 & 50.8 & \\
\hline
\end{tabular}

Table 4 Variables associated with dyspareunia in HIV-positive women with a sexual partner in the month before the interview

\begin{tabular}{llll}
\hline Variable & PR & 95\% Cl & p Value \\
\hline Vaginal dryness & 1.96 & 1.10 to 3.50 & 0.023 \\
Urinary incontinence & 1.86 & 1.06 to 3.27 & 0.031 \\
\hline $\begin{array}{l}\text { Poisson multiple regression }(n=124) . \\
\text { PR, prevalence ratio. }\end{array}$ & &
\end{tabular}

explanation for this finding may lie in the psychological problems generated by the infection itself, which may arise more frequently in stable relationships. ${ }^{27}{ }^{28}$ As one has not controlled for frequency of intercourse, one thought is that the dyspareunia is probably due a lower frequency of intercourse rather than an inferior quality of the relationship. Results of the bivariate analysis revealed an association between physical/emotional violence and dyspareunia. Violence is known to be associated with poorer psychological adjustment and adverse sexual health outcomes in women. ${ }^{29} 30$ In addition, having muscle pain was associated with dyspareunia in the bivariate analysis. This finding is in line with another study showing that musculoskeletal pain often interferes with sex and may be associated with dyspareunia. ${ }^{31} \mathrm{~A}$ borderline association was found between the use of lamivudine/zidovudine and dyspareunia; however, no explanation for this association was found in the literature. One may hypothesise that dyspareunia in these women could be due to the side effects of these drugs on depression.

There are some limitations to this study that must be taken into account. First, its cross-sectional design does not permit any conclusions to be drawn with respect to causality. It is also important to note that it was a clinical sample. So the results found in this study may not be extrapolated to the general population. Furthermore, there were some differences in the clinical characteristics of the HIV-positive and HIV-negative women. These differences could be attributed to the fact that the HIV-negative women were selected at specialist outpatient clinics providing care to menopausal women. By selecting HIV-positive women also in menopausal outpatient care, maybe groups would be similar. Nevertheless, multivariate analysis, conducted in a sufficiently large sample of women after controlling for confounding factors, confirmed that HIV infection was not significantly associated with dyspareunia. Good control of the HIV infection and the regular use of ART by the majority of the women may have brought this group of women closer to the HIV-negative group in terms of their characteristics.

\section{CONCLUSIONS}

In this study population, HIV infection was not associated with the presence of dyspareunia. The principal factors associated with dyspareunia in HIV-positive 
women were vaginal dryness and urinary incontinence. These data indicate a need for multidisciplinary care for HIV-positive menopausal women, paying particular attention to ensuring the women's compliance with ART and offering improved care when these two clinical situations are present to ensure that these women come as close as possible in this respect to HIV-negative women. Greater attention to dyspareunia as a potential component of women's general HIV and sexual care is warranted. A proactive approach to conversations about vulvovaginal atrophy would improve the management of dyspareunia and vaginal dryness. In addition to improving the quality of these women's sexual lives, we hypothesise that appropriate management of this issue may reduce the likelihood of lesions on the vaginal wall, which may act as a portal of entry for other infections.

\section{Collaborators Lívia Akl helped in the collection of data.}

Contributors ALRV, AMP-N and LC-P contributed to the conception or design. ALRV, DdCG, WCD and ASM contributed to the acquisition of data. MHdS, ALRV, AMP-N and LC-P contributed in the analysis of data. ALRV, AMP-N, LC-P and MHdS contributed in the interpretation of data. All the authors were involved in the drafting of the manuscript or revising it critically for intellectual content. All the authors gave final approval of the version to be published.

Funding The São Paulo Foundation for the Support of Research (Fundação de Amparo à Pesquisa do Estado de São Paulo-FAPESP), Grant \# 2010/ 06037-5.

Competing interests None.

Patient consent Obtained.

Ethics approval The project was approved by the internal review board of CAISM/UNICAMP and was conducted in compliance with the current version of the Declaration of Helsinki and with Resolution 196/96 of the Brazilian National Committee for Ethics in Research (CONEP) and its subsequent revisions.

\section{Provenance and peer review Not commissioned; externally peer reviewed.}

Data sharing statement We have used a questionnaire to collect data for this study. The instrument used to collect data is available by emailing anarvaladares@gmail.com

Open Access This is an Open Access article distributed in accordance with the Creative Commons Attribution Non Commercial (CC BY-NC 3.0) license, which permits others to distribute, remix, adapt, build upon this work noncommercially, and license their derivative works on different terms, provided the original work is properly cited and the use is non-commercial. See: http:// creativecommons.org/licenses/by-nc/3.0/

\section{REFERENCES}

1. Kao A, Binik YM, Kapuscinski A, et al. Dyspareunia in postmenopausal women: a critical review. Pain Res Manag 2008;13:243-54.

2. Sung SC, Jeng CJ, Lin YC. Sexual health care for women with dyspareunia. Taiwan J Obstet Gynecol 2011;50:268-74.

3. Lachowsky M, Nappi RE. The effects of oestrogen on urogenital health. Maturitas 2009;63:149-51.

4. Valadares AL, Pinto-Neto AM, Conde DM, et al. A population-based study of dyspareunia in a cohort of middle-aged Brazilian women. Menopause 2008;15:1184-90.

5. Graziottin A. Etiology and diagnosis of coital pain. J Endocrinol Invest 2003;26(3 Suppl):115-21.

6. Avis NE, Zhao X, Johannes CB, et al. Correlates of sexual function among multi-ethnic middle-aged women: results from the Study of
Women's Health Across the Nation (SWAN). Menopause 2005;12:385-98.

7. Kao A, Binik YM, Amsel R, et al. Biopsychosocial predictors of postmenopausal dyspareunia: the role of steroid hormones, vulvovaginal atrophy, cognitive-emotional factors, and dyadic adjustment. J Sex Med 2012;9:2066-76.

8. Pazmany E, Bergeron S, Verhaeghe J, et al. Sexual communication, dyadic adjustment, and psychosexual well-being in premenopausal women with self-reported dyspareunia and their partners: a controlled study. J Sex Med 2014;11:1786-97.

9. Florence E, Schrooten W, Dreezen C, et al.; Eurosupport Study Group. Prevalence and factors associated with sexual dysfunction among HIV-positive women in Europe. AIDS Care 2004;16:550-7.

10. Bova C, Durante A. Sexual functioning among HIV-infected women. AIDS Patient Care STDS 2003;17:75-83.

11. Collazos J. Sexual dysfunction in the highly active antiretroviral therapy era. AIDS Rev 2007;9:237-45.

12. Dennerstein L, Anderson-Hunt M, Dudley E. Evaluation of a short scale to assess female sexual functioning. J Sex Marital Ther 2002;28:389-97.

13. Valadares AL, Pinto-Neto AM, de Sousa MH, et al. [Sociocultural adaptation of the short personal experiences questionnaire (SPEQ) in Brazil]. Rev Bras Ginecol Obstet 2010;32:72-6.

14. Soules MR, Sherman S, Parrott E, et al. Executive summary: Stages of Reproductive Aging Workshop (STRAW) Park City, Utah, July, 2001. Menopause 2001;8:402-7.

15. Lambert S, Keegan A, Petrak J. Sex and relationships for HIV positive women since HAART: a quantitative study. Sex Transm Infect 2005;81:333-7.

16. Altman DG. Practical statistics for medical research. Boca Raton, FL: Chapman \& Hall/CRC, 1999.

17. Barros AJ, Hirakata VN. Alternatives for logistic regression in cross-sectional studies: an empirical comparison of models that directly estimate the prevalence ratio. BMC Med Res Methodol 2003;3:21.

18. Bell C, Richardson D, Wall M, et al. HIV-associated female sexual dysfunction: clinical experience and literature review. Int J STD AIDS 2006;17:706-9.

19. Wilson TE, Jean-Louis G, Schwartz R, et al. HIV infection and women's sexual functioning. J Acquir Immune Defic Syndr 2010;54:360-7.

20. Bray S, Gedeon J, Hadi A, et al. Predictive value of CD4 cell count nadir on long-term mortality in HIV-positive patients in Uganda. HIV AIDS 2012;4:135-40.

21. Laumann EO, Nicolosi A, Glasser DB, et al.; GSSAB Investigators' Group. Sexual problems among women and men aged 40-80 y: prevalence and correlates identified in the Global Study of Sexual Attitudes and Behaviors. Int J Impot Res 2005;17:39-57.

22. Levine KB, Williams RE, Hartmann KE. Vulvovaginal atrophy is strongly associated with female sexual dysfunction among sexually active postmenopausal women. Menopause 2008;15(4 Pt 1):661-6.

23. Parish SJ, Nappi RE, Krychman ML, et al. Impact of vulvovaginal health on postmenopausal women: a review of surveys on symptoms of vulvovaginal atrophy. Int $J$ Womens Health 2013:5:437-47.

24. Salonia A, Zanni G, Nappi RE, et al. Sexual dysfunction is common in women with lower urinary tract symptoms and urinary incontinence: results of a cross-sectional study. Eur Urol 2004;45:642-8.

25. Urwitz-Lane R, Ozel B. Sexual function in women with urodynamic stress incontinence, detrusor overactivity, and mixed urinary incontinence. Am J Obstet Gynecol 2006;195:1758-61.

26. Wehbe SA, Kellogg S, Whitmore K. Urogenital complaints and female sexual dysfunction. Part 2. J Sex Med 2010;7:2304-17.

27. Reis RK, Gir E. [Living with the difference: the impact of serodiscordance on the affective and sexual life of HIV/AIDS patients]. Rev Esc Enferm USP 2010;44:759-65.

28. Klusmann D. Sexual motivation and the duration of partnership. Arch Sex Behav 2002;31:275-87.

29. Laanpere M, Ringmets I, Part K, et al. Intimate partner violence and sexual health outcomes: a population-based study among 16-44-year-old women in Estonia. Eur J Public Health 2013;23:688-93.

30. Leclerc B, Bergeron S, Binik YM, et al. History of sexual and physical abuse in women with dyspareunia: association with pain, psychosocial adjustment, and sexual functioning. J Sex Med 2010;7 (2 Pt 2):971-80.

31. Rosenbaum TY. Musculoskeletal pain and sexual function in women. J Sex Med 2010;7(2 Pt 1):645-53. 